\section{MINIMISE ORAL SYMPTOMS OF MENOPAUSE}

When it comes to the menopause, women are susceptible to a number of potential symptoms, including burning mouth syndrome, periodontal disease, tooth loss, dry mouth and menopausal gingivostomatitis.

To spare your patients the unwanted oral effects that present during this stage in life, regular assessments and education on the importance of a good oral hygiene regimen are essential. For safe, gentle and effective prevention and treatment, try recommending solutions from the oral healthcare specialist, Curaprox.

With a winning combination of the CS 5460 manual toothbrush with ultra-fine CUREN filaments, CPS interdental brushes made with extra strong surgical wire, and CURASEPT ADS (Anti-Discolouration System) mouth rinse, your patients can achieve a good standard of oral health, helping to minimise potential menopause symptoms along the way.

For dry mouth, Curaprox provides a complete range of products, including salivary substitute gel, toothpaste, mouthwash, spray and gum.

Menopause can bring a number of unwelcome symptoms, but with your help patients don't need to suffer orally. Call Curaprox today to find out more about products available. For more information call 01480 862084, email info@curaprox. co.uk or visit www.curaprox.co.uk.

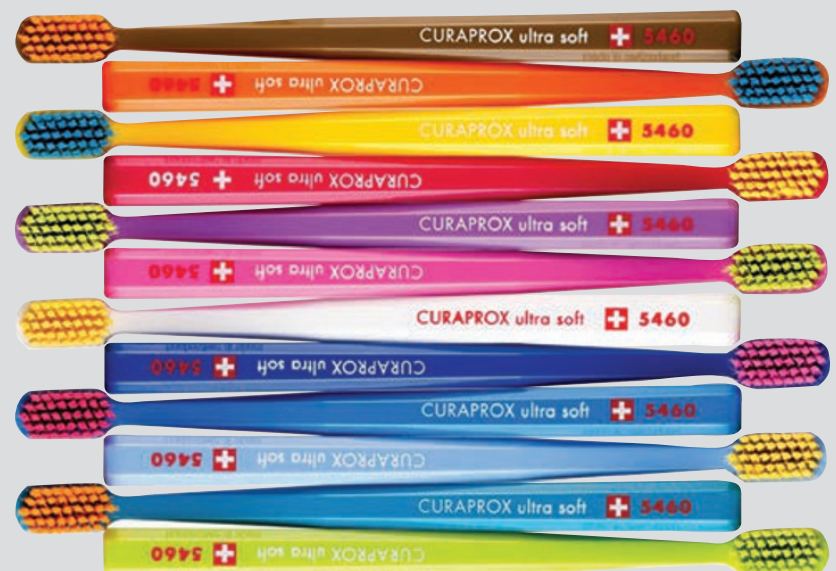

\section{NO DRYING CYCLE, LONG-TERM SERVICE AND SUSTAINABILITY}

In January 2018 CPAC Equipment, Inc. is launching their new RapidHeat Pro11 High-Capacity Table-Top Sterilizer.

Advanced engineering enables the Pro11 to compete with the industry's popular table-top steam sterilisers with $50 \%$ more capacity. The Pro11 uses the company's 'High-Velocity Hot Air' RapidHeat technology to perform a complete cycle in as little as six minutes. As no water or steam is used, the Pro11 has no drying cycle, requires very little maintenance, and comes with a standard three-year parts and labour warranty.

The Pro11 RapidHeat Tehcnology has been designed with long-term service and environmental sustainability - with independent laboratory testing confirming $85 \%$ less energy used per sterilisation cycle than comparable steam sterilisers. In addition, the same tests concluded that the RapidHeat Technology's waterless sterilisation environment does not contribute to instrument corrosion that has been proven to be common with steam sterilisation.

For more information email dbkaer@ cpac.com or visit www.cpacequipment.com.

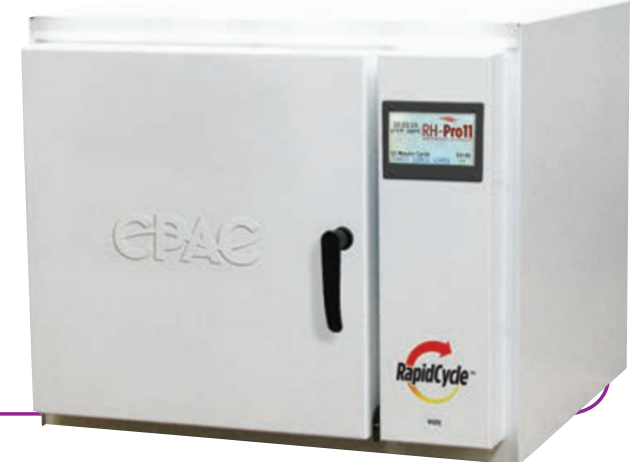

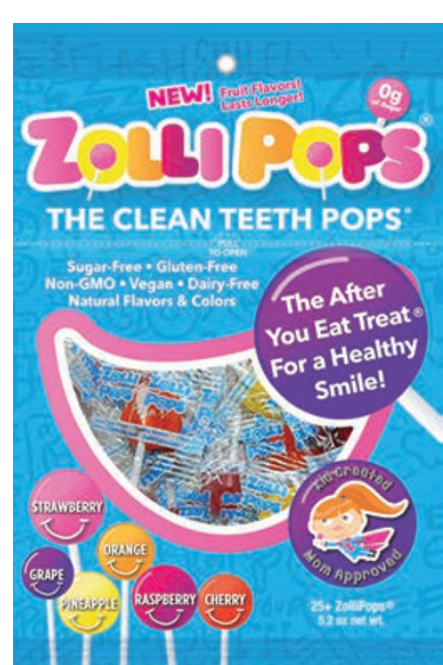

\section{SUGAR FREE} LOLLIPOPS THAT ARE GOOD FOR \section{THE TEETH}

Zollipops are all-natural, sugar free lollipops made with plant based sweeteners such as xylitol and erythritol. There have been numerous conclusive studies about the dental benefits the natural sweeteners possess and now for the first time they've been implemented into a range of children's sweets.

Steins Foods, the exclusive UK distributor, is extremely excited about working with the US brand and wants to not only educate parents on the benefits but also wants dentists to stand behind and promote the brand as a healthy and good way for parents to look after their children's teeth.

Zollipops were created when Alina Morse was seven-years-old; she went to the bank with her dad and the cashier offered her a lollipop. While she really wanted to accept, her parents always told her that sweets were terrible for her teeth. So she asked her dad, 'Why can't we make a lollipop that's actually good for your teeth?' In that moment the idea for Zollipops was born.

Dentists wanting to stock Zollipops can order in bulk direct from www. zollipops.co.uk. 